\title{
Underwater Laying of Pipes for Heating Networks of Energy Systems
}

\author{
Y. A. Gorinov ${ }^{1, *}$ \\ ${ }^{1}$ Volga State University of Technology, Yoshkar-Ola, Russia
}

\begin{abstract}
The article is devoted to the development of a new pipe-laying technology for heating networks of energy systems when crossing water barriers. In this paper a piping structure consisting of a carrier steel pipe enclosed in composite material for heat insulation and ballasting with an outer protective polyethylene casing is described. Theoretical and experimental studies of the structure are presented, mathematical models of the physicomechanical properties of the proposed composite material are developed, a technicaland-economic assessment is carried out.
\end{abstract}

\section{Introduction}

In the Russian Federation, the most developed heat supply system is central. The heat sources include about 585 heat electropower stations and more than 3000 heating boiler-houses with a capacity of more than 20 gigacalories per hour. Their share in the heat energy production is $73 \%$. The system of distributing thermal energy and heat-transfer agent from heat sources to the consumer is an important element of energy systems and complexes. The total length of double-pipe heating networks is over 177,000 kilometres.

Great national economic importance is given to the task of improving the efficiency and reliability of heat supply systems, which require addressing the rational use of fuel, material and labor resources, energy conservation, improvement of the environmental situation and ensuring a high level of energy supply to the population. Meeting these requirements of central heating systems has a number of advantages and helps to achieve the main goal of creating large sources of thermal energy with extensive heat networks. It should be noted that nowadays the level of design and construction of heating networks does not correspond sufficiently to modern requirements, which reduces the efficiency of energy systems in general. Advanced constructions and industrial technologies of laying pipes are slowly being introduced. The overwhelming majority of settlements are located along the shores of various water bodies, and therefore there is a dilemma for the development of the structure of the municipal heating and power complexes: either to develop local central heating systems for each part of the city divided by the water area, or to create a single heating system. In the latter case, the technical problem of crossing the water body when laying pipes requires solution. The easiest way to cross water barriers is known - laying a pipe along the rail and road transport bridges. However, existing bridge structures do not always have sufficient bearing capacity. In addition, the bridge may be missing in the appropriate place for tracing the pipes. Other wellknown solutions to this problem are the construction of suspended passages or the construction of an underwater pipe canal, which is a welded structure with cast-iron or concrete weights preventing it from coming to the water surface, inside of which pipes are arranged on the supports. Each of these methods has both advantages and disadvantages. Currently, materials and products of different nature and purposes are used for thermal insulation and ballasting of pipes. But none of the materials used does not have both the necessary ballasting and thermal insulation properties for laying the pipes under water. With the development of composite materials with a wide range of physicomechanical properties, it was possible to create the required material. This was the prerequisite for the development of a new way of crossing water barriers when laying pipes in a trench along the bottom of a basin. Various techniques and devices for laying underwater pipelines, materials for repair are discussed in [1-5]. The influence of external conditions on the strength characteristics of underwater pipelines are considered in [6-8]. Various thermal insulation coatings for subsea and buried pipelines are presented in [9-12]. The structure of the pipes for various ways of their laying are considered in the works of E.Y. Sokolov, V.I. Manyuk, A.A. Nikolaev, R.V. Shchekin, I.G. Staroverova, E.M. Avdolimova, Y.M. Varfolomeeva, A.A. Ionina, N.K. Gromova and others. [13-19] However, the authors did not consider the way of laying conduits across the water barriers along their bottom, the use of which provides the opportunity to choose the most cost-effective option of the technical solution enhancing the economic performance of energy systems and complexes. Thus, the development of new cost-effective pipe-laying technologies is an urgent task.

\footnotetext{
* Corresponding author: GorinovYA@ volgatech.net
} 
The scientific novelty of the present research is the following.

1. Based on both the system analysis of the existing regulatory and technical documentation and the results of previously performed scientific research, a new technology of laying pipes for central heating systems along the bottom of a water body using composite heatinsulating-and-ballast coating increases the efficiency of energy systems by increasing the actual radius of the heating network. Priorities of inventions are protected by patents of the Russian Federation: the utility patents No. 122746, No. 132895, and No. 136518.

2. The composition of the new composite material for the heat-insulation and ballasting is developed and experimentally substantiated. According to the obtained results, it is not inferior in its insulating properties to the modern materials used for pipes of heating networks ( $\lambda$ $=0.17-0.248 \mathrm{~W} / \mathrm{m} * \mathrm{~K})$. The priority of the invention is protected by the patent of the Russian Federation No. 2544194.

3. New data on the regularities of changes in density, thermal conductivity, and compressive strength of the developed composite material depending on its composition allowing the change prediction of its physical and mechanical properties and the use of energy systems for various operating conditions were obtained.

During the research, the methods of mathematical modelling and experimental design, probability theory and mathematical statistics were used; tests of the physicomechanical properties of the developed composite materials were carried out using actualized methods and certified equipment.

\section{The results of theoretical studies of ballasting ability and thermal conductivity}

The possibility of creating a piping structure that meets the conditions of its laying along the bottom of a body of water was assessed. The pipe construction consists of a carrier pipe enclosed in composite material with an outer protective polyethylene casing. The composite consists of Portland cement, barite and wood particles. Portland cement serves as a binder for the components. The use of barite as a ballasting filler is due to its high density ( $\rho=4700 \mathrm{~kg} / \mathrm{m} 3$ ). Wood particles having a coefficient of thermal conductivity $\lambda \approx 0.09-0.17$ $\mathrm{W} /(\mathrm{m} * \mathrm{~K})$ give the composite material the necessary thermal insulation properties. The design priority (Figure 1) is protected by the utility patent No. 122746 dated 10.12.2012.

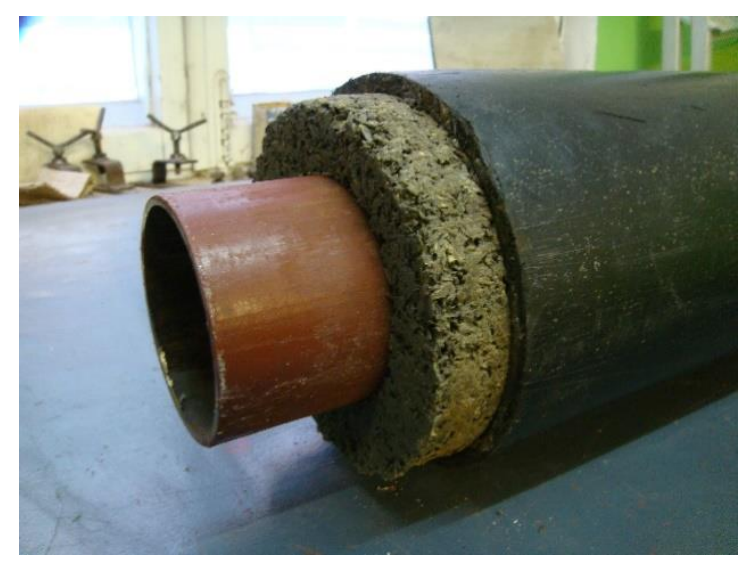

Fig. 1. The pipe construction in the form of a finished product.

\subsection{Results of theoretical studies of the ballasting ability of the structure}

The worst combination of loads occurs when the pipeline is not buried, i.e. located at the bottom of a basin in a trench. The ballasting capacity of the composite is determined on the basis of its density determined according to the law of additivity for the known density and volume fraction of the components.

According to the results presented in Table 1, an underwater pipe is resistant to coming to the water surface at the nominal diameter of $100 \mathrm{~mm}$ or more. If it is required to lay underwater pipes of nominal diameters of 50,70 , or $80 \mathrm{~mm}$, it is necessary to use additional ballasting weights of more than $16.73,11.32$, and 7.99 newton per linear meter, respectively.

\subsection{Results of theoretical studies of thermal conductivity}

The criterion for evaluating the effectiveness of the insulating material is its thermal conductivity. The classical solutions of the theory of generalized conductivity include the Maxwell equation for heterogeneous systems consisting of the continuous and dispersed phases. In the composite material, the continuous phase (matrix) is formed by Portland cement, barite and water in a bound state, and the wood particles uniformly distributed in the matrix form the dispersed phase. The coefficient of the thermal conductivity of the composite is determined by the following equation:

$$
\begin{gathered}
\lambda_{\text {cmps }}=\lambda_{1}\left(\frac{1-2 A B}{1+2 A B}\right) \approx \lambda_{1}(1-4 A B)= \\
=\lambda_{1} e^{-4 A B} \approx \lambda_{1} e^{-2 B}
\end{gathered}
$$

Where, $\lambda_{\text {cmps }}$ is the thermal conductivity coefficient of a heterogeneous system; $\lambda_{1}$ is the thermal conductivity coefficient of the continuous phase (matrix); $\lambda_{2}$ is the thermal conductivity coefficient of the dispersed phase; $v$ is the volume concentration of the dispersed phase. 
Table 1. The results of the study of the stability of an underwater pipe.

\begin{tabular}{|c|c|c|c|c|}
\hline $\begin{array}{l}\text { Nominal diameter } \\
\text { of a carrier steel } \\
\text { pipe, } D_{\mathrm{N}}, \mathrm{mm}\end{array}$ & $\begin{array}{l}\text { Flow drag } \\
\text { force, } \\
\mathrm{Px}_{\mathrm{X}}, \mathrm{N} / \mathrm{m}\end{array}$ & $\begin{array}{l}\text { Flow lifting } \\
\text { force, } \mathrm{P}_{Y} \\
\mathrm{~N} / \mathrm{m}\end{array}$ & $\begin{array}{l}\text { Drag force taking into } \\
\text { account shear stability } \\
\text { coefficient, ks.s., N/m }\end{array}$ & $\begin{array}{l}\text { Supporting force, } \mathrm{N} \text {, taking into } \\
\text { account the coefficient of friction } \\
\text { between a pipe and the ground, } \mathrm{fr}, \mathrm{N} / \mathrm{m}\end{array}$ \\
\hline 50 & 29.04 & 14.52 & 31.94 & 11.96 \\
\hline 70 & 29.04 & 14.52 & 31.94 & 20.62 \\
\hline 80 & 29.04 & 14.52 & 31.94 & 23.95 \\
\hline 100 & 32.67 & 16.34 & 35.94 & 36.89 \\
\hline 125 & 32.67 & 16.34 & 35.94 & 44.71 \\
\hline 150 & 57.17 & 28.59 & 62.89 & 63.08 \\
\hline 200 & 81.68 & 40.84 & 89.84 & 113.72 \\
\hline 250 & 90.75 & 45.38 & 99.83 & 149.59 \\
\hline 300 & 90.75 & 45.38 & 99.83 & 179.10 \\
\hline 400 & 101.64 & 50.82 & 111.80 & 226.24 \\
\hline 500 & 114.35 & 57.17 & 125.78 & 273.03 \\
\hline 600 & 128.87 & 64.43 & 141.75 & 363.46 \\
\hline 700 & 145.20 & 72.60 & 166.98 & 313.50 \\
\hline 800 & 163.35 & 81.68 & 187.85 & 301.46 \\
\hline 900 & 199.65 & 99.83 & 229.60 & 303.84 \\
\hline 1000 & 217.80 & 108.90 & 250.47 & 381.24 \\
\hline 1200 & 258.64 & 129.32 & 297.43 & 474.64 \\
\hline 1400 & 290.40 & 145.20 & 333.96 & 581.84 \\
\hline
\end{tabular}

$$
A=\frac{\lambda_{1}-\lambda_{2}}{\lambda_{2}+2 \lambda_{1}} \approx \frac{1}{2}
$$

$$
\begin{aligned}
& \mathrm{B}=\frac{\rho_{1}+\rho_{2}-2 \rho_{\text {cmps }}}{\rho_{1}+\rho_{2}-2 \rho_{3}}=\frac{1-\frac{2 \rho_{\text {cmps }}}{\rho_{1}+\rho_{2}}}{1-\frac{2 \rho_{3}}{\rho_{1}+\rho_{2}}} \approx \\
& \approx 1-\frac{2 \rho_{\text {cmps }}}{\rho_{1}+\rho_{2}}+\frac{2 \rho_{3}}{\rho_{1}+\rho_{2}}=1+\frac{2\left(\rho_{3}-\rho_{\text {cmps }}\right)}{\rho_{1}+\rho_{3}}
\end{aligned}
$$

The studies were performed using the Microsoft Office Excel program. The results were compared with the rated values of the average annual hourly specific thermal energy loss for the double-pipe water systems for the underground channelless laying according to Set of Rules (SR) of the Russian Federation for thermal insulation of equipment and pipelines 61.13330.2012.

According to the results presented in Table 2, the thermal insulation characteristics of the developed composite meet the requirements for thermal protection of pipes with a nominal diameter of $200 \mathrm{~mm}$ and more. The use of this insulation for pipes with a diameter of less than $200 \mathrm{~mm}$ is possible, but it needs to increase the thickness of the insulation.

\section{The results of an experimental study}

At the preliminary stage of the study, 10 samples of the cubic-shaped composite material with dimensions of

Table 2. The results of the study of the average annual hourly specific loss of heat, $\mathrm{W} / \mathrm{m}$.

\begin{tabular}{|c|c|c|c|c|c|}
\hline $\begin{array}{c}\text { Nominal diameter } \\
\text { of a pipe, } \\
\mathrm{D}_{\mathrm{N}}, \mathrm{mm}\end{array}$ & Calculated & $\begin{array}{c}\text { Standardized Set } \\
\text { of Rules } \\
61.13330 .2012\end{array}$ & $\begin{array}{c}\text { Nominal } \\
\text { diameter of a } \\
\text { pipe, } \\
\mathrm{D}_{\mathrm{N}}, \mathrm{mm}\end{array}$ & Calculated & $\begin{array}{c}\text { Standardized Set } \\
\text { of Rules } \\
61.13330 .2012\end{array}$ \\
\hline 50 & 68.99 & 41 & 400 & 139.11 & 148 \\
\hline 70 & 80.83 & 49 & 500 & 159.45 & 176 \\
\hline 80 & 89.24 & 52 & 600 & 175.88 & 205 \\
\hline 100 & 95.14 & 58 & 700 & 184.56 & 229 \\
\hline 125 & 111.44 & 66 & 800 & 193.38 & 257 \\
\hline 150 & 90.75 & 73 & 900 & 179.94 & 284 \\
\hline 200 & 92.73 & 93 & 1000 & 187.79 & 312 \\
\hline 250 & 102.25 & 106 & 1200 & 197.46 & 368 \\
\hline 300 & 117.74 & 121 & 1400 & 214.61 & 425 \\
\hline
\end{tabular}



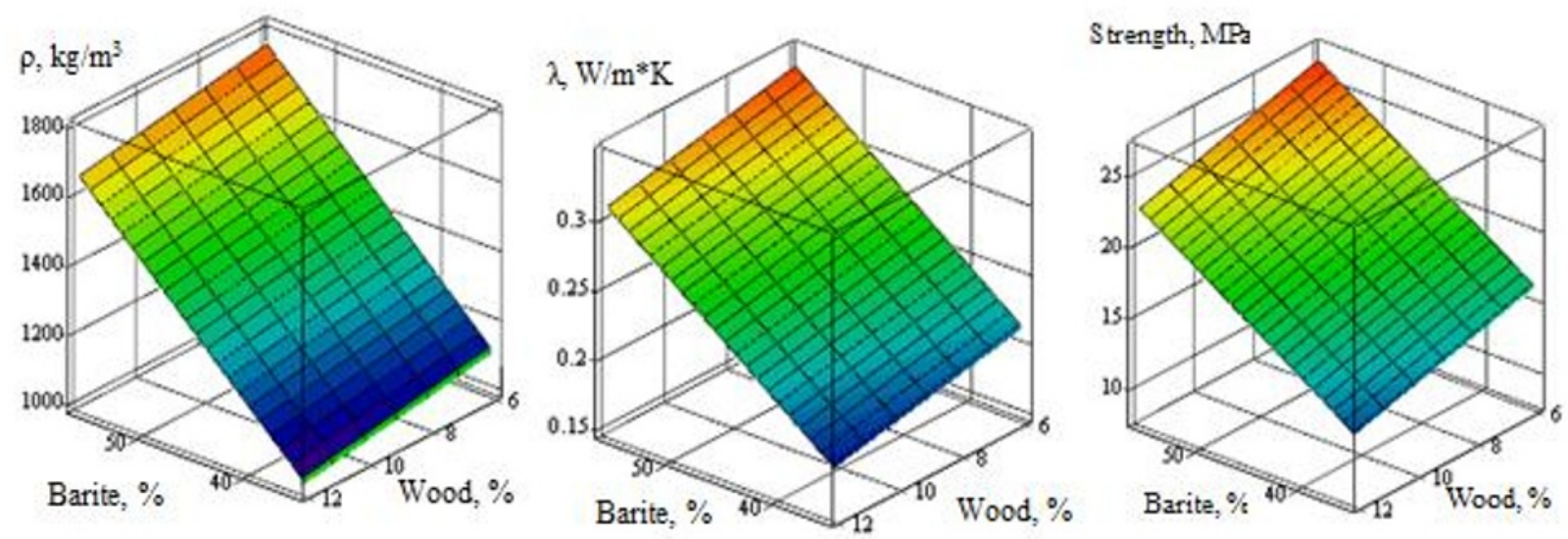

Fig. 2. The dependencies of the physicomechanical properties of the composite material on the content of barite and wood waste.

$150 \times 150 \times 150 \mathrm{~mm}$ were manufactured. The composition of the samples is the following: Portland cement, barite, chips, and water in the ratio of $1: 2: 4: 1.3$. Portland cement grade is M400 and meets the requirements of the State Standard of the Russian Federation 31108-2003, barite meets the requirements of the State Standard of the Russian Federation 3158-75, machine chips are of fraction $0.5-20 \mathrm{~mm}$, water meet the requirements of the State Standard of the Russian Federation 23732-79.

The statistical indicators necessary for the further research and calculations were determined by the method of the experimental design. To simplify the further research and calculations, the following assumptions were made: the ratio of components is determined in volumetric terms; the volume ratio of Portland cement is assumed to be constant and equal to one; the amount of water is determined by the coefficient of the water-cement ratio, at which the rated consistency for concrete is achieved in accordance with the State Standard of the Russian Federation 10181-62.

At the main stage of the experiment, the dependencies of the physicomechanical properties (density, thermal conductivity, and compressive strength) of the composite material on the content of barite and wood waste of different fractional composition (chips - 0.5-20 mm, sawdust - 0.1-3 mm, chips - 10-30 mm) were determined.

The developed composite has the required physicomechanical properties necessary for laying pipes for heating networks along the bottom of a basin. With an increase in the proportion of wood particles in the mixture from $50 \%$ to $71.4 \%$, the density of the composite material decreases for all types of fillers. With an increase in the proportion of wood particles from 50\% to $71.4 \%$, the thermal conductivity of the composite material decreases. With an increase in the content of wood particles from $50 \%$ to $71.4 \%$, the ultimate strength of the composite material decreases.

\section{Conclusions}

Based on the results of theoretical and experimental studies, it can be concluded that the proposed technical solution is promising for increasing the efficiency of energy systems and complexes.

The developed composite material has the required physicomechanical properties necessary for laying pipes for heating networks along the bottom of a basin. The underwater piping made of the developed composite is resistant to coming to the water surface if the nominal diameter of a carrier steel pipe is more or equal to 100 $\mathrm{mm}$. If needed to lay an underwater pipe of the nominal diameters of 50,70 , or $80 \mathrm{~mm}$, it is required to ballast it with additional weights of more than $16.7,11.32$, or 7.99 newton per linear meter, respectively. The insulating characteristics of the developed composite meet the requirements for the thermal protection of pipes with the nominal diameter of $200 \mathrm{~mm}$ and more. The use of this thermal insulation for pipes with a diameter of less than $200 \mathrm{~mm}$ is possible, but it needs to increase its thickness.

\section{References}

[1] N. Ming Chang, H. Anderson, Apparatus and method for laying underwater pipelines United States Patent 3616651, (1971)

[2] M. Jegousse, Method and apparatus for assembling and laying underwater pipeline United States Patent 4068490, (1978)

[3] J. Lamy, Laying of underwater pipelines United States Patent 4183697, (1980)

[4] M. Shamsuddoha, M. M. Islam, T. Aravinthan, A. Manalo., L. Kin-tak, Effectiveness of using fibre-reinforced polymer composites for underwater steel pipeline repairs Composite Structures 100, 40-54 (2013)

[5] Z. Zhang, B. Shi, Y. Guo., L. Yang, Numerical investigation on critical length of impermeable plate below underwater pipeline under steady current Science China Technological Sciences 56, 1232-1240 (2013)

[6] Croll J., A simplified model of upheaval thermal buckling of subsea pipelines Thin-Walled Structures 29, 59-78 (1997)

[7] N. Bouchonneau, V. Sauvant-Moynot, D. Choqueuse, F. Grosjean, E. Poncet, D. Perreux, 
Experimental testing and modelling of an industrial insulated pipeline for deep sea application Journal of Petroleum Science and Engineering 73, 1-12 (2010)

[8] O. Vestrum, M. Kristoffersen, M. PolancoLoria, H. Ilstad, M. Langseth, T. Børvik, Quasi-static and dynamic indentation of offshore pipelines with and without multi-layer polymeric coating Marine Structures 62, 60-76 (2018)

[9] M. Wilmott, J. Highams, R. Ross, A. Kopystinski, Coating and thermal insulation of subsea or buried pipelines Journal of Protective Coatings \& Linings 17, 47-54 (2000)

[10] D. Janoff, N. McKie, J. Davalath, Prediction of Cool Down Times and Designing of Insulation for Subsea Production Equipment Offshore Technology Conference (2004)

[11] N. Bouchonneau, V. Moynot, F. Grosjean, D. Choqueuse, E. Poncet, D. Perreux, Thermal Insulation Material for Subsea Pipelines: Benefits of Instrumented Full-Scale Testing To Predict the LongTerm Thermomechanical Behaviour Offshore Technology Conference (2007)

[12] J. Yang, M. Lourenço, S. Estefen, Thermal insulation of subsea pipelines for different materials International Journal of Pressure Vessels and Piping 168, 100-109 (2018)

[13] A. Nikolaev, Designer's Handbook. Heating network design (Moscow: Stroiizdat) 361 (1965)

[14] R. Shchekin, S. Korenevsky, G. Bem, F. Skorokhodko, E. Chechik, G. Sobolevsky, V. Melnik, O. Korenevskaya, Handbook of heating and ventilation. Book 1. Heating and Heat Supply (Kiev: Budivelnik) 416 (1976)

[15] V. Manuk, Y. Kaplinski, E. Hig, A. Manuk, V. Ilin, Adjustment and operation of heat networks (Moscow: Stroiizdat) 432 (1982)

[16] E. Avdolimov, A. Shalnov, Water heating networks (Moscow: Stroiizdat) 288 (1984)

[17] N. Gromov, et al. Water heating networks. Design Reference Guide, ed N K Gromov (Moscow: Energoatomizdat) 376 (1988)

[18] E. Sokolov, Central heating and heating network (Moscow: Moscow Power Engineering Institute) 472 (2001)

[19] U. Varfolomeev, O. Kokorin, Heating and heating networks (Moscow: INFRA-M) 480 (2006) 